\title{
Alexithymia and the Perception of Stress of Public Transport Drivers
}

\author{
L. Winklerová*, K. Paráková \\ Transport Research Centre, Brno, Czech Republic \\ *Corresponding author: leona.winklerova@cdv.cz
}

DOI: $10.2478 / v 10158-012-0046-8$

\begin{abstract}
The objective of the research was description of the factors of psychological stress of Czech drivers in association with an occurrence of alexithymia and with the number of accidents. Psychological stress, occurrence of alexithymia and the number of accidents were indicated in a questionnaire. The sample consisted of 611 public transport drivers from the Czech Republic. Alexithymia was assessed by a 20 -item Toronto Alexithymia Scale questionnaire. The level of stress was assessed by a questionnaire Stress of Public Transport Drivers. The occurrence of psycho-pathological symptoms was assessed by The Symptom Checklist-90. The drivers have shown only a low level of stress which did not differ by the vehicle type. Alexithymia occurred with $1 / 3$ of the drivers. The association of alexithymia and the perceived stress was confirmed; the association of alexithymia and stress and the number of accidents was not confirmed. Contrary to the expectation, the drivers showed a low level of stress. The interaction with passengers was revealed as the most significant stressor. In accordance with our expectation and prior studies, alexithymia highly correlated with the problems in the relationship with other people.
\end{abstract}

KEY WORDS: Alexithymia, work stress, public transport drivers.

\section{INTRODUCTION}

According to the national statistics, more than $20 \%$ of all sick leaves are caused by the illnesses of the muscular system. Following the illnesses of the respiration system, they are the second most frequent cause of sick leave (Zdravotnická statistika, 2011). The occupation of a driver is essentially demanding in terms of psychological and physical resistance of the individuals (see Rydstedt et al., 1998; Kompier \& Martino, 1995). The stress has an impact on the decision making process and, therefore, on the performance of a driver. Thus it might be one of the significant causes of traffic accidents. If a driver manages to cope with the task of driving a vehicle in heavy traffic under the stress, the stress often manifests elsewhere, and in the form of physical or psychological complications. Moreover, if the driver has certain personality traits which cause a limited capacity to cope with the excessive stress and a limited amount of adequate decision-making - as alexithymia is - the risk of negative impacts on the job increases. As a covering factor in the studies dealing with this topic the so called control theory is confirmed (Klein, 1991), which shows that the occupation of public transport (PT) drivers is demanding, especially in terms of great responsibility, but with a little control over the situation; the drivers do not have a large impact on the results of their work (Searle \& Bright, 2003; Evans \& Carrère, 1991). 
The studies of the population of professional drivers have confirmed the hypotheses that there is a direct association of physical difficulties with the deficits in the emotional awareness (Mehling \& Krause, 2005; Alperovitch-Najenson et al., 2010). Alexithymia is considered a personality trait, or a specific affective and cognitive style. The term alexithymia was introduced in the second half of the previous century by Sifneos (1972), who observed the typical characteristics in his patients with psychosomatic illnesses. Basically, it means that these people cannot recognize their own emotions or the emotions experienced by other people. Sifneos $(1972 ; 1996)$ defined alexithymia with the following characteristics:

- Individuals describe how they feel through their body symptoms, they are not able to associate their feelings with any images or ideas;

- They concentrate on the description of the situations in which they get such a feeling;

- They are not able to specify closely or explain what a particular feeling means;

- They seem to be less capable in communication, with a limited vocabulary.

The findings which we consider important concern the association of alexithymia and various kinds of somatic or psychosomatic illnesses. Alexithymia considerably increases the vulnerability towards illnesses (not only psychosomatic), and it is one of the important factors which influence the efficacy of the treatment intervention. Lumley et al. (1996; 2010) claim that alexithymia is effective at three levels: physiologic, biologic, and cognitive. It is confirmed that the physiological level of alexithymia impact on the health is through a level of cortisol in blood of the alexithymic patients (their body is therefore constantly in a stress mode). The biological level of impact goes through unhealthy behaviour in the form of various addictions (cigarettes, alcohol, and drugs), compulsive behaviour, unhealthy life style, eating disorders which are reactions to the incapability to manage the stress in an adaptive way. The cognitive level leads through the perception of unspecific bodily sensations as the symptoms of illness, and thus increased sensitivity to these symptoms, and thus also to the somatoform disorders.

According to the research (Mehling \& Krause, 2005; Singh et al., 2011), alexithymia has an impact on the ability to cope with stress adequately; and in our opinion, this deficit may show the problems connected with driving a motor vehicle; this fact may be more applicable to PT drivers. The occupation of PT driver is stressful; in terms of traffic: higher demands on concentration and the speed of decision making; as well as in terms of permanent interaction with passengers. With regard to the ability of alexithymic patients to cope with stress, we suppose that it transforms into psychosomatic difficulties. Therefore, these drivers should be offered training and education how to cope with emotions. According to the current knowledge of alexithymia as a personal trait which is associated with personal traits as behaviour of type A and hostility, it might be related also to the number of accidents.

\subsection{Objective and hypothesis}

The objective of this research is to describe the factors of psychological stress of Czech drivers and to find out the association of alexithymia with the perception of this psychological stress (distress); and moreover the number of accidents of the PT drivers. A further step is to apply the findings in a suggestion of specific programmes which will be focused on a real help to reduce the psychological stress of individuals. 


\section{METHODS}

\subsection{Description of population}

The total number of participants is 611 drivers from four transportation companies in the Czech Republic, namely in the towns: Brno, Ostrava, Liberec, and Plzeň. The representative sample consists of tram, bus, and trolley bus drivers. The sociodemographic characteristics of the sample are shown in Table 1.

The data was collected in the years 2012 and 2013. The motivation to take part in the research was a financial reward of 400 Czech Crowns. Each participant received a folder which contained a letter of instructions about anonymity and ethical properties of the data collection, and the battery of questionnaires. The battery consisted of the questionnaire concerning socio-demographic indicators of age, sex, marital status, driving practice and the number of driven kilometres, the number of accidents, and of the questionnaires shown below.

The study population consisted mainly of males (89\%), the majority of respondents had a degree (88.1\%). Accidents in the last year were reported by $27.3 \%$ respondents. The cohort consisted of bus drivers, tram drivers and trolleybus drivers.

Table 1: Characteristics of study participants $(n=611)$.

\begin{tabular}{|lcc|}
\hline & & Mean (S.D.) or \% \\
\hline \hline Age & & $46(10.3)$ \\
\hline Sex & Female & $10 \%$ \\
& Male & $89 \%$ \\
\hline Education & & \\
\hline & Primary school & $4.1 \%$ \\
& Graduation & $88.1 \%$ \\
& University & $5.7 \%$ \\
\hline Marital status & & \\
\hline & Single & $17.8 \%$ \\
& Married & $54.1 \%$ \\
& Divorced & $24.2 \%$ \\
& Widowed & $2.5 \%$ \\
\hline Accidents & & $27.3 \%$ \\
\hline SMHD (stress) & & $67.468(31.029)$ \\
\hline & Tramway & $73.016(29.693)$ \\
& Bus & $63.923(30.809)$ \\
& Trolleybus & $68.268(32.628)$ \\
\hline TAS (alexithymia) & & $31.8 \%$ \\
\hline
\end{tabular}

\subsection{Questionnaires}

\section{Stress of PT drivers (SMHD)}

In order to assess the subjective perception of stressful situations when doing the job of PT driver, a questionnaire was designed. The questionnaire consists of 54 statements which are assessed by a proband on the scale 0 (it does not bother/stress me) to 4 (it bothers/stresses me a lot). 
In terms of the psychometric qualities, the questionnaire has shown to be reliable. The reliability was inspected by the inner consistency; hence the Cronbach's alpha was 0.955.

\section{Toronto Alexithymia Scale (TAS-20)}

The questionnaire used the Czech version of the Toronto Alexithymia Scale (HoškováMayerová \& Mokrá, 2010). The scale consists of three subscales: a) difficulty identifying emotions (TAS_DIF) (items: 1, 3, 6, 7, 9, 13, 14); b) difficulty describing emotions (TAS_DDF) (items: 2, 4, 11, 12, 17) and c) external-oriented thinking (TAS_EOT) (items: 5, $8,10,15,16,18,19,20)$. The items $4,5,10,18$ and 19 are negatively coded. The respondents are asked to express their agreement with the given statements (1... I definitely do not agree to $5 . .$. I absolutely agree). The total score is between 20 to 100 points. The authors divided the scale by two limiting values: 51 and 61. The score 51 and less correspond to the individuals without alexithymia traits, the score 61 and more correspond to the individuals with alexithymia traits. The interval $\{51 ; 61\}$ refers to "possible alexithymia”. Some studies (e.g. Taylor et al., 1997; 2008; Guttman \& Laporte, 2002) may work with the respondents of this score.

\section{Symptom Checklist (SCL)}

SCL consists of 90 items assessed by a five-point scale from $0 \ldots$ absolutely not to $4 \ldots$ very much. SCL measures nine primary dimensions of anxiety: somatization, obsession and compulsion, interpersonal sensitivity, depression, anxiety, hostility, phobic anxiety, paranoid ideation, psychoticism. Total score is between 0-360. The respondents scoring 224 and more are in a serious danger of psychopathology (Preuper et al., 2007).

\section{RESULTS}

The statistical analysis was made using the IBM SPSS Statistics 19. The descriptive statistics are presented in Tab. 1. To detect the links between alexithymia, level of stress and accidents, the correlation analysis (Pearson correlation coefficient) and t-test for independent samples were used.

The distribution of alexithymia is $6.8 \%$ in the sample of drivers (score in TAS-20 more than 61 points), with respect to the fact that this group counts only 19 drivers out of the total number of respondents, thus corresponding with the recommendations of authors of the scale. The drivers with possible alexithymia scoring between 51 and 60 were also included in the increase of the number of respondents for the statistical analysis; thus the rate of alexithymia in the sample rose to $31.8 \%$.

The level of stress is relatively low. Most respondents scored the value 1 or 2 in the SMHD questionnaire, which indicates moderate level of stress. The mean level of stress in the sample is 67.468 with standard deviation of (S.D.) 31.029. The highest value of stress were found for tram drivers 73.016 with S.D. 29.693, then followed by the trolleybus drivers 68.268 (S.D. 32.628), the smallest value of stress had bus drivers 63.923 (S.D. 30.809).

The association of the level of stress with alexithymic traits is significant, nevertheless, relatively weak (0.249). We found significant differences by comparing the groups of stressed and not stressed respondents (by SMHD score) according to the alexithymia characteristics (see Table 3). The respondents with more emotional trouble, who have alexithymic characteristics, e.g. difficulty identifying and describing feelings, are more stressed than the respondents who have good emotional awareness and vice versa (based on t-test for independent samples). 
As shown in Table 2, there is a significant association between alexithymic traits and all the subtests of Syndrom checklist (SCL-90). There seems to be a stronger significant association with interpersonal sensitivity (0.424) and hostility (0.404).

The correlation analysis did not confirm the association between alexithymia, level of stress and the number of accidents.

Table 2: Alexithymia, level of stress and number of accidents.

\begin{tabular}{|ll|l|}
\hline & & TAS sum \\
\hline SCL & & \\
\hline & Somatization & $0.233^{*}$ \\
& Obsession and compulsion & $0.319^{*}$ \\
& Interpersonal sensitivity & $0.424^{*}$ \\
Depression & $0.373^{*}$ \\
Anxiety & $0.382^{*}$ \\
Hostility & $0.404^{*}$ \\
Phobic anxiety & $0.359^{*}$ \\
Paranoid ideation & $0.326^{*}$ \\
Psychoticism & $0.359^{*}$ \\
\hline SMHD & & $0.249^{*}$ \\
\hline Accidents & -0.051 \\
\hline
\end{tabular}

* Significant effects at $\mathrm{p}$-value $\leq 0.05$ are indicated for all variables.

Table 3: Emotional difficulties and level of stress.

\begin{tabular}{|l|l|l|}
\hline Emotional difficulties & Level of stress** & Mean \\
\hline \multirow{2}{*}{$\begin{array}{l}\text { Difficulty identifying feelings (DIF) } \\
*\end{array}$} & 1 & 11.76 \\
\cline { 2 - 3 } $\begin{array}{l}\text { Difficulty describing feelings (DDF) } \\
*\end{array}$ & 2 & 13.55 \\
\cline { 2 - 3 } & 2 & 11 \\
\hline \multirow{2}{*}{ Externally oriented thinking (EOT) } & 1 & 13 \\
\cline { 2 - 3 } & 2 & 21.44 \\
\hline \multirow{2}{*}{ TAS sum* } & 1 & 31.96 \\
\cline { 2 - 3 } & 2 & 44.31 \\
\hline
\end{tabular}

* Significant effects at $\mathrm{p}$-value $\leq 0.001$.

** 1 = not stressed; 2 = stressed

\section{DISCUSSION}

The research aimed to verify the association of alexithymia and the level of stress of PT drivers. Based on the studies, the research focused on the association of alexithymia and the level of stress and the number of accidents of the drivers.

Contrary to our expectations, the analysis showed that public transport drivers are not under major work stress. The general level of stress in the studied cohort is relatively low. The respondents perceive the work related stress as little to moderate. This finding might be related to the inability of PT drivers to adequately assess the situation and adequately 
evaluate their condition. Another possible reason is a self-defence mechanism of denial which helps the drivers to cope with everyday stress. On the other hand, the PT drivers should be selected so that they are able to cope with the higher level of stress. Therefore, it is possible that in our selected cohort the stressors do not constitute high, above the limit, stress. The low association with psychosomatic difficulties supports this fact.

The study did not confirm our expectation about the association of alexithymia, the level of stress and the number of accidents. It does not show that alexithymia or distress would be significant factors in the occurrence of accidents. The finding might be influenced by the methodology of data collection. The number of accidents was assessed by a subjective interview with the respondents when we asked them how many accidents they caused and did not cause last year. We may assume that the respondents were afraid to say this information.

As expected, the study confirmed the association of alexithymia and the level of stress of professional drivers. The results show that for drivers who are more stressed it is difficult to be aware of their emotions and work with them correctly. It can be especially dangerous in situations where it is necessary to recognize the emotional reactions and behaviour of others (e.g. road users) and predict their future behaviour. It shows that drivers who are not able to recognize emotions in themselves have a problem to recognize emotions of other people. The result refers to psychosomatic problems of individuals with higher level of alexithymia in relation to higher level of stress (Lumley et al., 1996; Taylor et al., 2008).

If we focus more deeply on drivers' personality, there seems to be a considerable association of alexithymia and hypersensitivity, defined as hypersensitivity to the interpersonal relations, easily hurt feelings. The finding is in accord with other studies that explored the relation to the social environment, i.e. to people (Spitzer et al., 2005). Thus the conclusion that alexithymic people, in our case PT drivers, have more interpersonal problems, and in social contact they are not assertive are confirmed. In contrast to our expectation, the research did not show significant association of alexithymia with somatic problems and depression. There is a small correlation, but with regard to the prior studies (Lumley et al., 1996; Honkalampi et al., 2000) it was expected a much higher one. A significant association was found between alexithymia and psycho-pathologic symptoms assessed by the Syndrome Checklist; they are the scales of interpersonal sensitivity, hostility and anxiety; these relations are obvious as they describe alexithymic patients as they are: hypersensitivity to their emotional reactions and to the interaction with people in which there is incorporated emotional reaction to the reactions of others (in SCL interpersonal hypersensitivity), emotional behaviour is associated with fear and anxiety on the one hand (in SLC anxiety); and on the other hand, presumably as a defensive mechanism against anxiety. In terms of emotional awareness it would be appropriate to focus on the area of interpersonal relationships, which is a significant predictor of stress and alexithymia.

\section{CONCLUSION}

The authors worked with a sample of 611 PT drivers from four transport companies in the Czech Republic. The main objective of the research was to identify the basic factors of psychological stress of PT drivers, and to find out the level of impact or association of alexithymia and the perceived stress, and the number of accidents. The objective of the study was partially confirmed. The work with emotions is also important for the occupation of driver because of everyday contact with emotions, and thus the impossibility to avoid this interaction, i.e. the stressor. The work with drivers should be particularly focused on the area of emotions, more specifically on better identification and necessity of adequate reactions to emotions as well as to emotions of other road users. 


\section{ACKNOWLEDGEMENT}

This article was prepared with the help of project No. TA02030170 "MATRIX" funded by the Technology Agency of the Czech Republic.

We thank the transportation company of Brno, Liberec, Plzeň and Ostrava; and particularly the drivers for their participation.

\section{REFERENCES}

Alperovitch-Najenson, D. et al., 2010. Low back pain among professional bus drivers: ergonomic and occupational-psychosocial risk factors. The Israel Medical Association Journal, 12 (1), pp. 26-31.

Evans, G.W., Carrère, S., 1991. Traffic Congestion, Perceived Control, and Psychophysiologica Stress Among Urban Bus Drivers. Journal of Applied Psychology, 76 (5), pp. 658-63.

Guttman, H., Laporte L., 2002. Alexithymia, Empathy, and Psychological Symptoms in a Family Context. Comprehensive Psychiatry, 43 (6), pp. 448-455.

Honkalampi, K., Hintikka, J.,Tanskanen, A., Lehtonen, J., Viinama, H., 2000. Depression Is Strongly Associated With Alexithymia In The General Population. Journal of Psychosomatic Research, 48 (1), pp. 99-104.

Hošková-Mayerová, Š., Mokrá., T., 2010. Alexithymia among students of different disciplines. Procedia Social and Behavioral Sciences, 9, pp. 33-37.

Klein, H., J., 1991. Control Theory and Understanding Motivated Behavior: A different conclusion. Motivation and Emotion, 15 (1), pp. 29-44.

Kompier, M., A., J., Martino, V., D., 1995. Review of bus drivers'occupational stress and stress prevention. Stress \& Health, 11 (1), pp. 253-262.

Lumley, M., A., Stettner, L., Wehmer, F., 1996. How Are Alexithymia And Physical Illness Linked? A Review And Critique Of Pathways. Journal od Psychosomatic Research, 41 (6), pp. 505-518.

Lumley, M., A., Neely, L., C., Burger, A., J., 2010. The Assessment of Alexithymia in Medical Settings: Implications for Understanding and Treating Health Problems. Journal of Personality Assessement, 89 (3), pp. 230-246.

Mehling, W., E., Krause, N., 2005. Are difficulties perceiving and expressing emotions associated with low-back pain? The relationship between lack of emotional awareness (alexithymia) and 12-month prevalence of low-back pain in 1180 urban public transit operators. Journal of Psychosomatic Research, 58 (1), pp. 73-81.

Preuper, H. R. S., Reneman, M.F., Boonstra, A.M., Dijkstra, P.U.,Versteegen, G.J., Geertzen, J.H.B., 2007. The relationship between psychosocial distress and disability assessed by the Symptom Checklist-90-Revised and Roland Morris Disability Questionnaire in patients with chronic low back pain. The Spine Journal, 7 (5), pp. 525-530. 
Rydstedt, L., W., Johansson, G., Evans, G.W., 1998. A longitudinal study of workload, health and well-being among male and female urban bus drivers. Journal of Occupational and Organizational Psychology, 71 (1), pp. 35-45.

Searle, B., Bright, J. E. H., 2003. Bus driving: A bad job for all or a good job for some? Australian Journal of Psychology, 55, pp. 143.

Sifneos, P., E., 1972. Short Term Psychotherapy And Emotional Crisis. Harvard University Press.

Sifneos, P. E., 1996. Alexithymia: Past and Present. The American Journal of Psychiatry, 153 (7), pp.137-142.

Singh, K., Arteche, A., Holder, M. D., 2011. Personality factors and psychopathy, alexithymia and stress. Asian Journal of Psychiatry, 4 (1), pp. 35-40.

Spitzer, C., Siebel-Jürges, H., Barnow S., Grabe, H. J, Freyberger, H. J., 2005. Alexithymia and Interpersonal Problems. Psychotherapy and Psychosomatics, 74 (4), pp. 240-246.

Taylor, G. J., Bagby, M. R., Parker, J. D. A., 1997. Disorders of Affect Regulation: Alexithymia in Medical and Psychiatric Illness. Cambridge University Press.

Taylor, G. J., Bagby, M. R., Parker, J. D. A., Keefer, K. V., 2008. Latent Structure of the Alexithymia Construct: A Taxometric Investigation. Psychological Assessment, 20 (4), pp. 385-396.

Zdravotnická statistika, 2011. Ukončené prŕípady pracovní neschopnosti pro nemoc a úraz. ÚZIS ČR. (in Czech) 